\title{
Development of probabilistic risk assessment methodology of decay heat removal function against combination hazard of low temperature and snow for sodium-cooled fast reactors
}

\author{
Hiroyuki NISHINO*, Hidemasa YAMANO* and Kenichi KURISAKA* \\ * Japan Atomic Energy Agency \\ 4002 Narita-cho, Oarai, Ibaraki 311-1393, Japan \\ E-mail: nishino.hiroyuki@jaea.go.jp
}

Received: 15 February 2018; Revised: 25 May 2018; Accepted: 4 June 2018

\begin{abstract}
A probabilistic risk assessment (PRA) should be performed not only for earthquake and tsunami which are major natural events in Japan but also for other natural external hazards. However, PRA methodologies for other external hazards and their combination have not been sufficiently developed. This study is aimed at developing a PRA methodology for the combination of low temperature and snow for a sodium-cooled fast reactor which uses the ambient air as its ultimate heat sink to remove decay heat under accident conditions. The annual exceedance probabilities of low temperature and of snow can be statistically estimated based on the meteorological records of temperature, snow depth and daily snowfall depth. To identify core damage sequence, an event tree was developed by considering the impact of low temperature and snow on decay heat removal systems (DHRSs), e.g., a clogged intake and/or outtake for a DHRS and for an emergency diesel generator, an unopenable door on necessary access routes due to accumulated snow, failure of intake filters due to accumulated snow, and possibility of water freezing in cooling circuits. Recovery actions (i.e., snow removal and filter replacement) to prevent loss of DHRS function were also considered in developing the event tree. Furthermore, considering that a dominant contributor to snow risk can be failure of snow removal around intakes and outtakes caused by loss of the access routes, this study has investigated effects of electric heaters installed around the intakes and outtakes as an additional countermeasure. By using the annual exceedance probabilities and failure probabilities, the event tree was quantified. The result showed that a dominant core damage sequence caused by a snow and low temperature combination hazard is the failure of the electric heaters and the loss of the access routes for snow removal due to low temperature and snowfall which last for a day, and daily snowfall depth of $2 \mathrm{~m} /$ day.
\end{abstract}

Keywords : Probabilistic risk assessment, Combination hazard, Decay heat removal system, Core damage frequency, Dominant core damage sequence

\section{Introduction}

A probabilistic risk assessment (PRA) for natural external hazards is increasingly recognized as an important safety assessment method especially after the TEPCO's Fukushima Daiichi nuclear power station accidents. To guide seismic PRAs, the Atomic Energy Society of Japan (AESJ) published a seismic PRA standard (AESJ, 2007) and the AESJ has vigorously developed a tsunami PRA standard (AESJ, 2012). Currently, external hazards other than earthquake and tsunami, e.g., snow, low temperature, are recognized as important issues for nuclear power plant safety. In particular, risk assessments against various external hazards and their combination are demanded.

Experts of plant safety have studied screening methods to select hazards with a large impact on a nuclear power station because there are many types of natural external hazards. A method for selecting a single hazard with large impact has been studied by defining criteria for the screening (Kuramoto et al., 2014). A method for selecting a combination hazard has also been studied. One of previous studies selected a combination hazard by calculating the occurrence frequency after defining criterion for selecting a combination hazard from a viewpoint of occurrence freqency and its 
influence (Chen, 2016). Another previous study suggested a method for selecting a combination hazard by calculating risk factor (i.e., (the product of two hazard impact) $\times$ (the product of two hazard frequency) ) (Narumiya et al., 2016). Japan Society of Maintenology (JSM) studied significant interaction induced by combining two or more hazards and released a guideline to select a combination hazard which has a large impact by defining criteria for the screening (JSM, 2014). The combination hazard of snow and low temperature could affect greatly intake filters necessary for maintaining function of safety-related structures, systems and components (SSCs). Accumulated snow might clog intakes and/or outtakes outside the reactor building, while snow blowing into the filters inside of the building does not accumulate on the filters inside because it melts. On the other hand, in the case of the combination hazard of snow and low temperature, snow on the filters does not melt due to low temperature even inside the building, and the filters are clogged with snow. This satisfies one of the criteria of JSM - the influence of one external hazard is further affected by the other external hazard to increase its degree. Based on this screening guideline, the combination hazard of snow and low temperature is so significant that engineers have to develop safety measures.

Snow PRAs have been studied for light water reactors (LWRs) and sodium-cooled fast reactors (SFRs). One of previous studies calculated a core damage frequency (CDF) focusing on the maximum thickness of accumulated snow in terms of hazard intensity (Bareith et al., 2014). Another study calculated a CDF focusing not only on the maximum thickness of snow, but also on the daily snowfall depth and the snowfall duration time (Yamano et al., 2016). The method developed by the latter can analyze the effects of snow removal on CDF reduction by considering the snow accumulation speed and its duration time.

Hazard curve estimation and the PRA for low temperature have been studied for LWRs. The previous studies of hazard curve estimation for low temperature selected daily minimum temperature as hazard intensity and the hazard curve was described by using the Gumbel distribution (Kovacs and Spenlinger, 2016). The low temperature PRA for LWRs calculated a CDF by supposing a scenario in which sea water intakes are blocked by frazil ice (Puuka et al., 2015). On the other hand, unlike an LWR, decay heat removal systems (DHRSs) of an SFR can keep its function even if its sea water systems fail because an SFR's final heat sink under accident conditions is the ambient air. Considering the influence of the combination hazard of snow and low temperature, how long low temperature lasts is needed to assess the quantity of snow accumulates on the filters. This study, therefore, needs to select duration of low temperature as a hazard intensity and assesses a hazard curve of the duration.

Japan Atomic Energy Agency (JAEA) has been developing SFRs in Japan. To solve issues in the PRA for the combination hazard of snow and low temperature for an SFR, JAEA has developed a preliminary PRA for the combination considering their influences and recovery actions such as snow removal and filter replacement (Nishino et al., 2017). This paper describes the latest PRA methodology development for the combination of snow and low temperature, in which further safety measures (i.e., installing electric heaters around the intakes and outtakes) are added to the previous study to enhance the safety. In addition, it presents in detail how the occurrence frequency of eventsfrom an initiating event to core damage - is obtained simply by point estimation method.

In line with generic PRA procedures, this PRA consists of four steps: 1) the estimation of the combination of snow and low temperature; 2) the development of an event tree to identify core damage sequence; 3 ) the calculation of failure probabilities for SSCs; and 4) the quantification of an event tree. Details of each step are described in Sections 2 to 5.

\section{Occurrence frequency estimation of the combination hazard}

It is necessary to consider three hazard intensities (i.e., daily snowfall depth, snowfall duration time, and low temperature duration time) against the combination of snow and low temperature. The annual exceedance probability of each hazard intensity can be estimated from meteorological records, and then the occurrence frequency of the combination can be estimated from these probabilities.

\subsection{Daily snowfall depth and snowfall duration time}

The annual exceedance probabilities of snowfall depth and daily snowfall depth have been estimated based on the historical data recorded by Japan Meteorological Agency (2016) in the previous study (Yamano et al., 2016). The daily snowfall depth means the height of accumulated snow per day. The snowfall depth in this paper means the total height of the following: the snow height accumulated in a day; the snow height which has already accumulated before the day; 
and the snow height melted. In other words, the total will be addition of the first two heights minus the height of melted snow. The snowfall depth is used directly to describe a failure criterion to open a roof door in the event of abnormal snowfall and a criterion to clog the intake or outtake with snow as mentioned in Sections 4.2 and 4.4.

On one hand, the failure probability of snow removal depends on snowfall duration as mentioned in Section 4.4. Likewise, the failure probability of filter replacement depends on the duration of the combination hazard as mentioned in Section 4.6. Assuming that daily snowfall depth is constant in this study, the snowfall depth can be estimated by multiplying the daily snowfall depth by the duration time. It means that the snowfall depth can be replaced with the snowfall duration time. Taking these into account, snowfall duration time is more suitable than snowfall depth as the hazard intensity. In this study, snowfall duration time is defined as the snow depth by dividing the daily snowfall depth. Based on this definition, the snowfall depth is translated into the snowfall duration time, then the annual exceedance probability of the snowfall duration time is obtained.

\subsection{Low temperature duration time}

The hazard intensity of low temperature is selected as follows. The cooling circuits in a support system can freeze and/or the filters can be clogged with ice when ambient temperature is $0^{\circ} \mathrm{C}$ or below for a long time. From this reason, "low temperature" is defined as temperature of $0^{\circ} \mathrm{C}$ or below and the duration time of low temperature is selected as important hazard intensity in this study.

As estimated in the previous study (Nishino et al., 2017), the present study collected dates and times when the lowest temperature in a year was observed from the historical records between 1961 and 2010 of Japan Meteorological Agency (2016). These dates and times were assumed to be included in the longest duration time of the low temperature in the year which was regarded as the annual longest duration time of the low temperature. The plotting position formula (Tamori and Kyoshi, 2009) was applied to these annual longest duration time data to obtain the discrete annual probability of exceedance. Then this discrete probability is fitted to continuous probability distribution (e.g., Gumbel distribution) with the least squares method to estimate continuous annual exceedance probability as shown in Fig. 1.

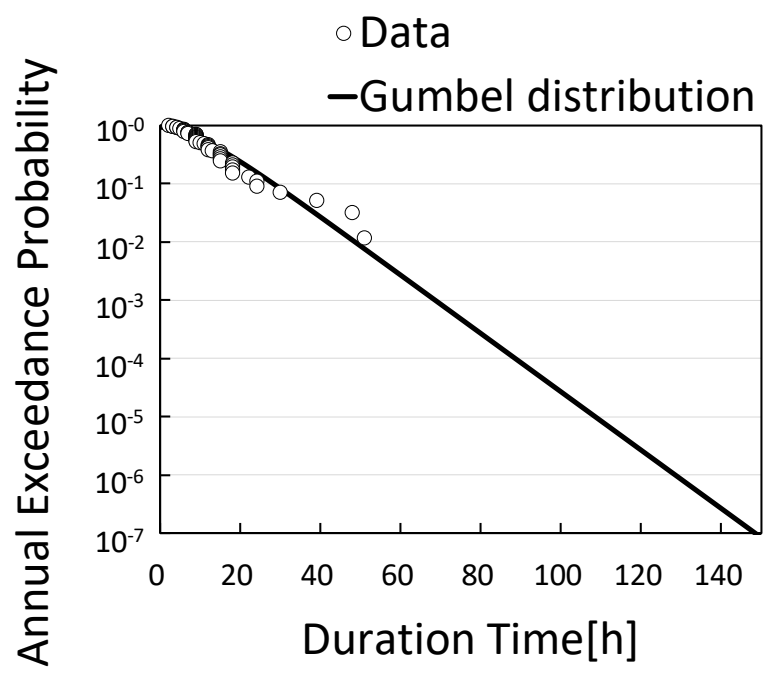

Fig. 1 Plotted circles are discrete probabilities obtained by applying the plotting position formula to data, and the curve is Gumbel distribution which is fitted to these discrete probabilities for range until $50 \mathrm{~h}$ (Based on Nishino et al., 2017).

\subsection{Occurrence frequency of the combination hazard}

This study assumes that there is no correlativity between the three hazard intensities and these intensities are discretized and categorized for the numerical calculation of the CDF and for the identification of the range of dominant hazard intensity as shown in Tables 1 to 3 . The daily snowfall depth was grouped every $1 \mathrm{~m} /$ day; 0 to $1 \mathrm{~m} /$ day is defined as 1 , in the same manner, 1 to $2 \mathrm{~m} /$ day is 2,2 to $3 \mathrm{~m} /$ day is 3 , and 3 to $4 \mathrm{~m} /$ day is 4 . Likewise, the duration times of snow and low temperature were grouped by the day; day 0 to 1 is defined as 1 , day 1 to 2 is 2 and so on. Tables 1 to 3 also show the estimation results of interval frequency of the categorized daily snowfall depth and interval probabilities of the 
categorized duration times of snow and low temperature. The occurrence frequency of the combination hazard can be estimated by multiplying the interval frequency and the interval probabilities corresponding to the categorized hazard intensities. To simplify the estimation, this study conservatively assumed the numerical values in the column of $1 \mathrm{~m} /$ day in Table 2 as the interval probabilities of snowfall duration time for various daily snowfall depths.

If it snows over a long periods of time, for which there is no precedent, daily snowfall might be abnormally deep and duration times of snow and low temperature might be abnormally long. In this case, the depth might be dependent on low temperature as oppose to the above assumption, and duration times of snow and low temperature might have correlativity. The case with the correlativity can be assumed that duration times of snow and low temperature are equal, and the occurrence frequency of the combination hazard can be estimated by multiplying the interval frequency of daily snowfall depth and the interval probabilities of the duration times of snow or low temperature.

Table 1 Frequency of categorized daily snowfall depth.

\begin{tabular}{|c|c|c|}
\hline \multicolumn{2}{|c|}{ Daily snowfall depth } & \multirow{2}{*}{ Frequency [/year] } \\
\cline { 1 - 2 } Range[m/day] & Value [m/day] $(*)$ & \\
\hline 0 to 1 & 1 & $3.3 \times 10^{+0}$ \\
\hline 1 to 2 & 2 & $7.4 \times 10^{-3}$ \\
\hline 2 to 3 & 3 & $8.3 \times 10^{-6}$ \\
\hline 3 to 4 & 4 & $9.3 \times 10^{-9}$ \\
\hline
\end{tabular}

(*): Representative value of hazard intensity range.

Table 2 Joint probability of categorized combination of snowfall duration time and daily snowfall depth.

\begin{tabular}{|c|c||c|c|c|c|}
\hline \multicolumn{2}{|c||}{ Snowfall duration time } & \multicolumn{4}{c|}{ Value $(*)$ of daily snowfall depth } \\
\hline Range [day] & Value [day] $(*)$ & $1 \mathrm{~m} /$ day & $2 \mathrm{~m} /$ day & $3 \mathrm{~m} /$ day & $4 \mathrm{~m} /$ day \\
\hline 0 to 1 & 1 & $8.5 \times 10^{-1}$ & $1.4 \times 10^{-1}$ & $7.4 \times 10^{-3}$ & $3.7 \times 10^{-4}$ \\
\hline 1 to 2 & 2 & $1.4 \times 10^{-1}$ & $3.7 \times 10^{-4}$ & $9.2 \times 10^{-7}$ & $2.3 \times 10^{-9}$ \\
\hline 2 to 3 & 3 & $7.4 \times 10^{-3}$ & $9.2 \times 10^{-7}$ & $1.1 \times 10^{-10}$ & $1.5 \times 10^{-14}$ \\
\hline 3 to 4 & 4 & $3.7 \times 10^{-4}$ & $2.3 \times 10^{-9}$ & $1.5 \times 10^{-14}$ & $\varepsilon$ \\
\hline 4 to 5 & 5 & $1.9 \times 10^{-5}$ & $5.7 \times 10^{-12}$ & $\varepsilon$ & $\varepsilon$ \\
\hline 5 to 6 & 6 & $9.2 \times 10^{-7}$ & $1.5 \times 10^{-14}$ & $\varepsilon$ & $\varepsilon$ \\
\hline 6 to 7 & 7 & $4.6 \times 10^{-8}$ & $\varepsilon$ & $\varepsilon$ & $\varepsilon$ \\
\hline 7 or longer $(* *)$ & 8 & $2.3 \times 10^{-9}$ & $\varepsilon$ & $\varepsilon$ & $\varepsilon$ \\
\hline
\end{tabular}

(*): Representative value of hazard intensity range.

$\varepsilon<1 \times 10^{-15}$.

$(* *)$ : Probability of 10 day or longer at $1 \mathrm{~m} /$ day is $\sim 6 \times 10^{-12}$.

Table 3 Probability of categorized low temperature duration time.

\begin{tabular}{|c|c|c|}
\hline \multicolumn{2}{|c|}{ Low temperature duration time } & \multirow{2}{*}{ Probability } \\
\cline { 1 - 2 } Range[day] & Value [day] $(*)$ & \\
\hline 0 to 1 & 1 & $7.8 \times 10^{-1}$ \\
\hline 1 to 2 & 2 & $1.5 \times 10^{-1}$ \\
\hline 2 to 3 & 3 & $1.0 \times 10^{-2}$ \\
\hline 3 to 4 & 4 & $6.3 \times 10^{-4}$ \\
\hline 4 to 5 & 5 & $4.0 \times 10^{-5}$ \\
\hline 5 to 6 & 6 & $2.5 \times 10^{-6}$ \\
\hline 6 to 7 & 7 & $1.6 \times 10^{-7}$ \\
\hline 7 or longer & 8 & $1.0 \times 10^{-8}$ \\
\hline
\end{tabular}

(*): Representative value of hazard intensity range. 


\section{Event tree of the combination hazard}

\subsection{Decay heat removal system of SFR}

A loop type SFR which has DHRS with three loops and an alternative DHRS with one loop is used in this study. The SFR model plant and systems related to decay heat removal are illustrated in Fig. 2. A single loop of the DHRS has capacity to remove decay heat by forced circulation or natural circulation of sodium. The alternative DHRS also has capacity to remove decay heat by the forced circulation. The forced circulation mode requires e.g. pumps for sodium circulation in the loop, air blowers for air cooler, and emergency power supply system for system support. On the other hand, in the natural circulation mode the decay heat can be removed just by regulating air flow in air cooler with manual damper operation at the air cooler of the DHRS even if these pumps, air blowers and/or emergency power supply system fail.

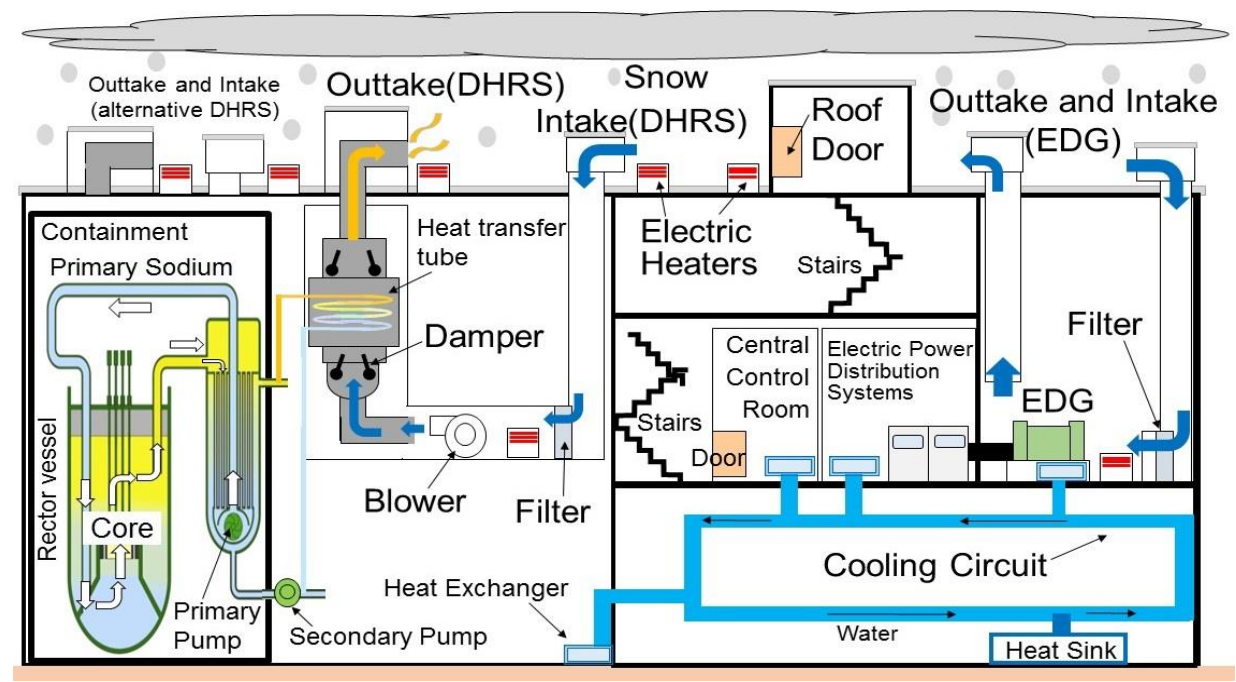

Fig. 2 SFR model plant and systems related to decay heat removal.

\subsection{Impacts of Snow}

This section describes impacts of abnormal snow which has heavy load on a reactor building and abnormal snowfall depth by which the intakes and/or outtakes are clogged that are necessary for maintaining function of SSCs, i.e., emergency diesel generator (EDG), the DHRS and the alternative DHRS.

As for the abnormal snow load, an earthquake-resistant reactor building assumed in this study is robust and has resistance to snowfall depth up to $10 \mathrm{~m}$. The snowfall depth exceeding $10 \mathrm{~m}$ is out of scope in this study because its frequency is extremely low as shown in Tables 1 and 2.

If the intakes and/or outtakes of the EDG are clogged, the EDG and an emergency power supply system fail due to loss of offsite power. If the intakes and/or outtakes for air coolers of the DHRS and the alternative DHRS are clogged, decay heat cannot be removed. Since the failure of these SSCs has a large impact on the decay heat removal, this study identified the EDG, the DHRS, the alternative DHRS, and their intakes and outtakes as important SSCs for branch points in the event tree.

Countermeasures against the above-mentioned snow clogging events should be considered to apply our PRA method to make realistic situations. In this study, therefore, the implementation of snow removal and the installation of electric heaters were assumed as accident management strategies. Even if the intakes and outtakes are clogged with snow, snow removal by plant personnel can recover the function of the intakes and outtakes. Installing electric heaters around the intakes and outtakes can also recover the function. Furthermore, installing electric heaters around a roof door of the reactor building can secure the access routes. The electric heaters are operated remotely in the central control room in this study. 
In addition, the power transmission lines of offsite power might be damaged by oscillation of the lines when snow accumulated on them falls down. In this study, loss of offsite power was conservatively assumed a priori to pay more attention on the functional failure of the on-site SSCs.

\subsection{Impact of low temperature}

This section describes impacts of low temperature by which sodium can freeze in heat transfer tubes in the DHRS and/or in the alternative DHRS. If sodium freezes in the heat transfer tube of the air cooler, both forced and natural circulation for decay heat removal cannot be achieved. Further, we conservatively assumed that a part of the cooling circuits shown in Fig. 2 is influenced by low ambient temperature and water can freeze. This circuit supports the emergency power supply system, active components, and so on to be required for the forced circulation mode. The freezing of water in the circuit causes the loss of the forced circulation in the DHRS and its alternative. Taking these influences into account, the air cooler and the cooling circuits were identified as important SSCs for branch points in the event tree.

This study assumed that plant personnel can wrap the pipes of the cooling circuits with heat insulating material or can keep the water running by opening valves in the cooling circuits as accident management.

\subsection{Impact of the combination hazard}

Clogging of the filters with snow is a consequence by the combination hazard. The intake filters of the EDG and of the air cooler in the DHRS and/or in the alternative DHRS can be clogged with snow if snow blows into the reactor building (like snow storm) and accumulates on the filters and stays there as ice due to low temperature. If the filters are clogged, the filters fail by pressure difference between inside and outside of the filters. In this case, snow and cold air enter into the reactor building through holes in the damaged filter, and the inside can be severe atmosphere which can cause the failure of the EDG and/or freezing of sodium in the heat transfer tube. Taking it into account, this study identified the filters as important SSCs for branch points in the event tree.

This study assumed that plant personnel can replace the filters as accident management before the filters are clogged, and frozen snow on the filters can be melted by the electric heaters.

\subsection{Event tree}

Considering the important SSCs and the safety measures, the event tree to identify core damage sequence was developed as shown in Fig. 3, where headings in the event tree were defined in Table 4 and initiating event is assumed as a loss of offsite power. As shown in the definitions of code $\mathrm{H} 1, \mathrm{H} 2$ and $\mathrm{H} 3$ in the event tree, we assume that chance to aware the need is three times and if all of the chances fail, it results in the failure of decay heat removal because the intakes and outtakes are clogged with snow. If plant personnel are aware of snowfall, plant personnel are required to remove snow on the access routes to secure the routes (routes from a central control room to the intakes and outtakes on the roof of a reactor building through the roof door) as definition of codes AD, EH1 and AR in the event tree. If snow depth reaches the height of bottom edge of the roof door and/or hinges of the roof door is frozen due to low temperature, plant personnel cannot open the door by hand. However, as defined in code EH1, even in this case, they can melt the accumulated snow and the frozen hinges by remote operation of the electric heaters installed around the roof door, and can open the door.

Once plant personnel opened the door successfully, they will remove snow on the routes from the door to the intakes and outtakes on the roof of the reactor building (as definition of code AR) and around the intakes and outtakes (as definition of codes DS, AS and MS). If snow around the intakes and outtakes is removed, the related SSCs (i.e., EDG, the DHRS and its alternative) can maintain their function. Even if plant personnel lose the access routes for snow removal, they can melt snow around the intakes and outtakes with the electric heaters installed nearby as definition of codes EH 2, 3 and 4.

To maintain the emergency power supply, the water in the cooling circuits needs to be prevented from freezing by wrapping heat insulating materials around pipes of the cooling circuits or by running the water in the pipes by opening valves, as definition of code AW. 


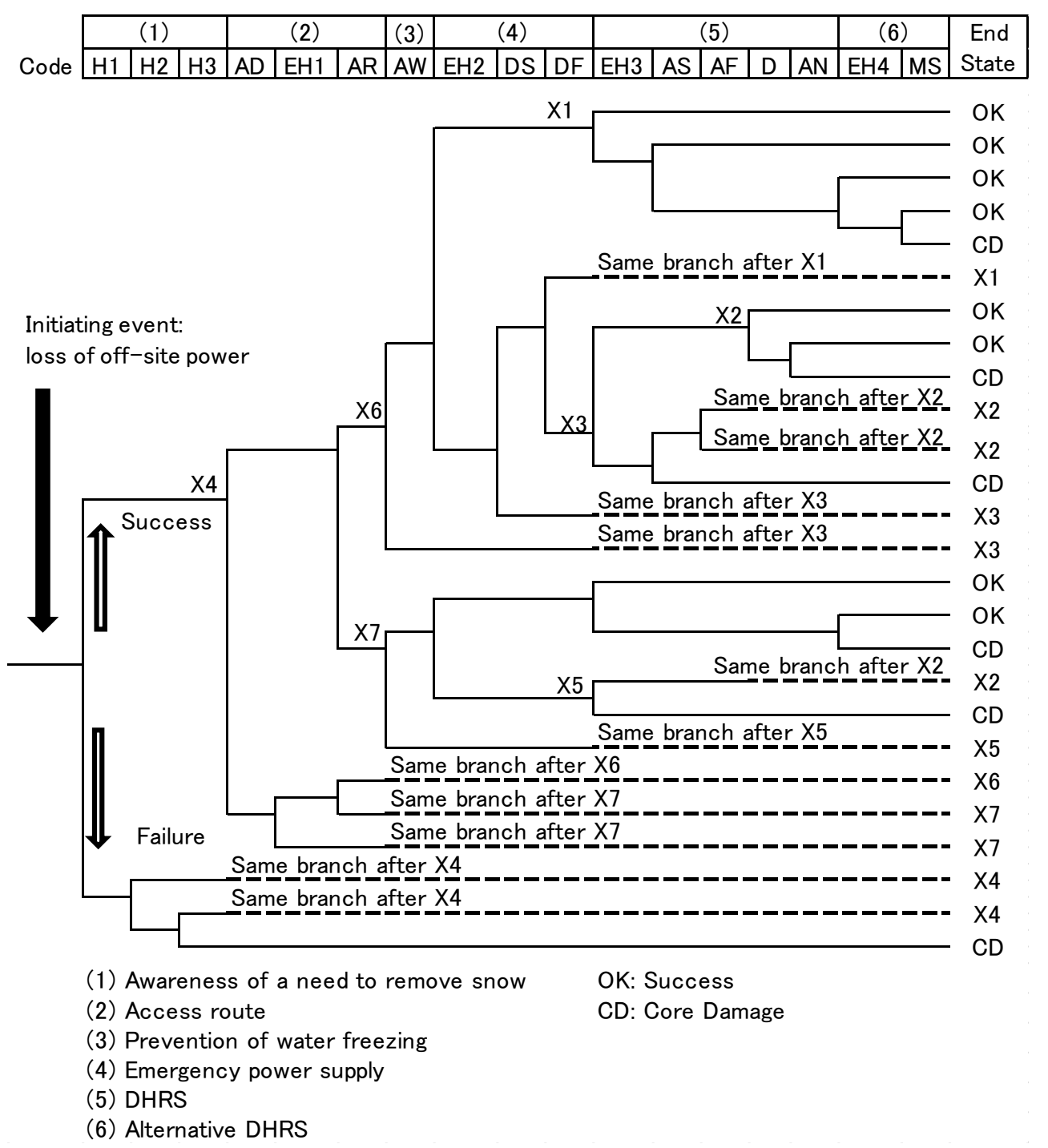

Fig. 3 An event tree is developed to identify core damage sequence by assuming a loss of offsite power induced by the combination hazard of low temperature and snow. The branches in the event tree are defined by success or failure in maintaining the function of the important SSCs and in implementing the safety measures against the combination hazard. The dash line of end state "Xi $(\mathrm{i}=1,2,3,4,5,6,7)$ " in the event tree is the same as branches in the right side of Xi defined on a solid line.

Once the electric heaters around the intakes and outtakes start operating, the electric heaters can melt not only snow around the intakes and outtakes but also frozen snow on the filters. If the electric heaters fail, the filters near the failed heaters are replaced by plant personnel as definition of codes DF and AF.

As above scenarios, when the emergency power supply is secured, snow around the intakes and outtakes and the frozen snow on the filter are removed; therefore, SFR can remove decay heat of the DHRS and/or its alternative in the forced circulation mode. If one or more of these fails, the forced circulation mode fails.

When the electric heater for the DHRS fails and plant personnel fail to replace the filter of the DHRS, the filter is clogged and fails. If snow and cold air enter the room of the air cooler through holes in the damaged filter, the condition of the room can be severe. Based on this, air temperature near the air cooler intake is assumed to vary from $0^{\circ} \mathrm{C}$ to $-5^{\circ} \mathrm{C}$. In addition, if the manual operation of the DHRS dampers in the natural circulation mode fails to regulate air flow in the air cooler, the change of air temperature may cause freezing of sodium in the heat transfer tube of the air cooler, as defined code D. If regulation of the dampers opening fails, uncontrolled air flow might stochastically freeze sodium in the heat transfer tube, as defined code AN. When plant personnel remove snow around the intake and outtake for the DHRS and regulate the dampers opening, decay heat can be removed by the natural circulation mode of the DHRS. Even 
if personnel fail to regulate the opening of the dampers manually, it is assumed that decay heat can be removed by the natural circulation mode of the DHRS when plant personnel remove snow around the intake and outtake for the DHRS. As a result, the sodium freezing in the heat transfer tube is stochastically prevented.

Table 4 Definition of Event Tree Headings.

\begin{tabular}{|c|l|}
\hline Code & \multicolumn{1}{|c|}{ Definition } \\
\hline H1 & Awareness of the snow removal and filter replacement necessity in first chance. \\
\hline H2 & Awareness of the snow removal and filter replacement necessity in second chance. \\
\hline H3 & Awareness of the snow removal and filter replacement necessity in third chance. \\
\hline AD & Opening the roof door by hand to secure the access routes. \\
\hline EH1 & Opening the roof door by the electric heater installed around the roof door for the access routes. \\
\hline EH2 & Securement of the intake and outtake of EDG by the electric heaters installed around its intake and outtake. \\
\hline EH3 & $\begin{array}{l}\text { Securement of the intake and outtake of the DHRS by the electric heaters installed around its intake and } \\
\text { outtake. }\end{array}$ \\
\hline EH4 & $\begin{array}{l}\text { Securement of the intake and outtake of the alternative DHRS by the electric heaters installed around its } \\
\text { intake and outtake. }\end{array}$ \\
\hline AR & Snow removal on routes from the roof door to the intake and outtake on the roof of reactor building. \\
\hline DS & Snow removal around the intake and outtake for EDG \\
\hline AS & Snow removal around the intake and outtake for air cooler of the DHRS \\
\hline MS & Snow removal around the intake and outtake for air cooler of the alternative DHRS \\
\hline AW & Prevention of the water freezing in the cooling circuits to support the emergency power supply system \\
\hline DF & Filter replacement for EDG \\
\hline AF & Filter replacement for the DHRS \\
\hline D & $\begin{array}{l}\text { Regulation of air flow in the air cooler by operating the dampers manually of the DHRS in the natural } \\
\text { circulation mode. }\end{array}$ \\
\hline AN & Prevention of sodium freezing in the heat transfer tube by uncontrolled air flow \\
\hline
\end{tabular}

\section{Failure probability at branch point}

\subsection{Awareness of a need to remove snow (codes H1, H2 and H3)}

In the previous study (Yamano et al., 2016), the failure probability of awareness of a need to remove snow and to replace the filters has been estimated at $8.5 \times 10^{-4}$. On one hand, plant personnel can easily get local weather information in a variety of ways to recognize the need to take the accident management actions. Taking this into account, the failure probability of the awareness is assumed to be $8.5 \times 10^{-5}$, which is $1 / 10$ times lower than the previous estimation.

\subsection{Access routes (code AD)}

Once plant personnel recognize the need of removing snow, they can open the roof door and secure the routes on the roof to reach the intakes and/or outtakes. First of all, this study estimated the failure probability to open the roof door.

The scenario in Section 3 assumes that plant personnel cannot open the roof door by hand when the snow depth reaches the bottom edge of the door and/or the hinges of the door freeze due to low temperature. In the previous study (Yamano et al., 2016), a target external hazard was solely snow and it was assumed that the roof door failed to open at the snow depth (height) of $1.0 \mathrm{~m}$ or deeper. On the other hand, the present study considers both the impacts of snow and low temperature. Taking into account the freezing of the hinges, it was assumed that the roof door fails to open at the snow depth of $0.8 \mathrm{~m}$ or deeper.

Figure 4 shows the time flow of plant personnel action and the cumulative probability distribution of time to reach the front of the roof door. The hazard occurs at $0 \mathrm{~h}$. Snow depth reaches the height at which snow removal is needed at $\bar{t}[\mathrm{~h}]$, where the height is assumed as $0.2 \mathrm{~m}$ in this study. It takes $t_{a}-\bar{t} \quad$ h] for plant personnel to become aware of the need of the snow removal. After they are aware of it, it takes $t_{b}-t_{a}$ [h] for them to reach the roof door. After time $\bar{t}$ $[\mathrm{h}]$, the roof door becomes unable to open due to snow accumulation reaching snow depth $0.8 \mathrm{~m}$. When $t_{b} \quad[\mathrm{~h}]$ is shorter than $\overline{\boldsymbol{t}}[\mathrm{h}]$, plant personnel can open the roof door. On the other hand, when $t_{b}[\mathrm{~h}]$ is longer than $\overline{\boldsymbol{t}}[\mathrm{h}]$, plant personnel cannot open the roof door. 


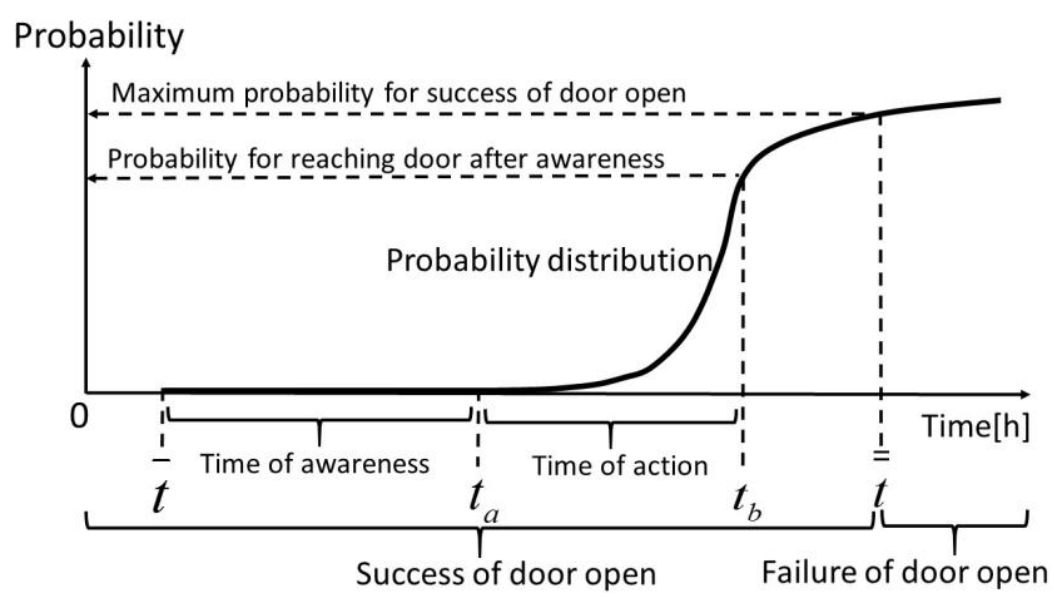

Fig. 4 Time flow of personnel action for opening the roof door after the hazard occurs, time limit for opening the door under the hazard condition, and cumulative probability distribution of time to reach front of the roof door.

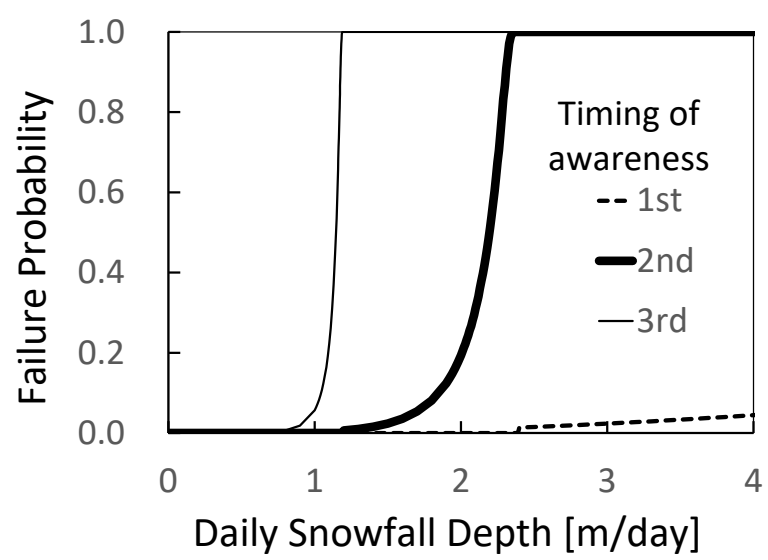

Fig. 5 The curves are failure probabilities to open the roof door. Curve with label "1st" means failure probability in plant personnel work from 0 to $8[\mathrm{~h}]$ after the hazard occurs (i.e., first plant personnel team). In the same way, curves with label "2nd" and "3rd" mean failure probabilities in plant personnel work from 8 to 16[h] (i.e., second plant personnel team) and from 16 to $24[\mathrm{~h}]$ (i.e., third plant personnel team), respectively.

The failure probability to open the roof door is estimated here based on time until the snow depth reaches $0.8 \mathrm{~m}$. For estimating the failure probability, it was assumed that, on average, it takes $1.0 \mathrm{~h}$ (about 0.04 day) for plant personnel become aware of the need of the snow removal after snow accumulated $0.2 \mathrm{~m}$ and it takes 10 min (about $7.0 \times 10^{-3}$ day) to reach the roof after the awareness. The logarithmic times to the awareness and to the action were assumed to be normally distributed with the standard deviation of about $1.5 \mathrm{~h}$ (about 0.06 day) and $3 \mathrm{~min}\left(2.1 \times 10^{-3}\right.$ day), respectively. The probability density functions of those times are expressed with $f(t)$ and $g(t)$, respectively. The success probability $p_{1}$ and failure probability $p_{2}$ for opening the roof door are expressed as follows,

$$
\begin{aligned}
& p_{1}(\bar{t} \bar{t})=\int_{0}^{\bar{t}-\bar{t}}\left[\int_{0}^{\bar{t}-\left(t^{\prime}+\bar{t}\right)} g\left(t^{\prime \prime}\right) \mathrm{d} t^{\prime \prime}\right] f\left(t^{\prime}\right) \mathrm{d} t^{\prime} \\
& p_{2}(\bar{t}, \bar{t})=1-p_{1}(\bar{t} \bar{t})
\end{aligned}
$$

where integration variables are $t^{\prime}=t_{a}-\bar{t}$ and $t^{\prime \prime}=t_{b}-t_{a}$. Ranges of these integration variables are $0 \leq \underline{\underline{t}} \dot{\underline{t}} \leq \bar{t}-\bar{t}$ and $0 \leq t^{\prime \prime} \leq \bar{t}-\left(t^{\prime}+\bar{t}\right)$ because ranges of variable $t_{a}$ and of variable $t_{b}$ are assumed $\bar{t} \leq t_{a} \leq \bar{t}$ and $t_{a} \leq t_{b} \leq \bar{t}$, where $\bar{t}$ and $\overline{\bar{t}}$ are constant under the condition that the daily snowfall depth is constant. The failure probability was obtained by subtracting the cumulative probability in the logarithmic normal distribution from 1.0, as Eq.(2). Since the time 
reaching $0.8 \mathrm{~m}$ of snow depth depends on the daily snowfall depth, the failure probability can be calculated at each of the daily snowfall depth. It was assumed that plant personnel work in three shifts around the clock, and chance for the awareness comes every $8.0 \mathrm{~h}$. Based on the above assumptions, the failure probability to open the roof door is calculated by using Eq.(1) and (2). The results are shown in Fig. 5.

Even if plant personnel cannot open the door by hand, they can melt snow around the door and frozen hinges using the electric heaters. The failure probability of the electric heaters is described in Section 4.3.

After opening the door, plant personnel are required to secure the routes on the roof to reach the intakes and outtakes. In this study, snow removal is identified as an important measure to secure these routes. If the snow removal fails, plant personnel lose these routes. The failure probability of the snow removal is described in Section 4.4.

\subsection{Electric heaters (codes EH1, EH2, EH3 and EH4)}

It was assumed that the electric heaters can be powered by a battery for $120 \mathrm{~h}$ ( 5 days). When the battery is drained, the electric heaters lose their function. Moreover, even if the electric heaters can operate for $120 \mathrm{~h}$ (days), the heaters can fail by three causes; 1) the main unit of the electric heater fails; 2) the battery fails; 3) plant personnel press a wrong button to start the electric heaters in the central control room. Taking them into account, the probability of this failure of the electric heater was assumed to be 0.1 .

\subsection{Snow removal (codes AR, DS, AS and MS)}

The intakes and outtakes can be clogged with only snow. It was assumed that the snow is removed once a day until it stops snowing. Based on this, the failure probability of the snow removal is estimated per total number of times. As estimated in previous study (Yamano et al., 2016), the failure of snow removal was defined as the condition that the daily snowfall depth exceeds the snow removal speed, and the snow removal speed was assumed to be normally distributed with mean speed of $4 \mathrm{~m} /$ day and with the standard deviation of $0.5 \mathrm{~m} /$ day. The failure probability of the snow removal is estimated in Fig. 6.

On one hand, the required number of times of snow removal is obtained by comparing the product of the daily snowfall depth and snowfall duration time with the snowfall depth at which the intake and/or outtake can be clogged with snow. It is assumed that the clogging snowfall depths for the intake and/or outtake of the EDG, DHRS and alternative DHRS are $1.5 \mathrm{~m}, 1.5 \mathrm{~m}$, and $1.0 \mathrm{~m}$ respectively in this study. Therefore, given the daily snowfall depth and the snowfall duration time, the failure probability for each intake and/or outtake of removing snow per the number of required snow removal is shown in Fig. 6.

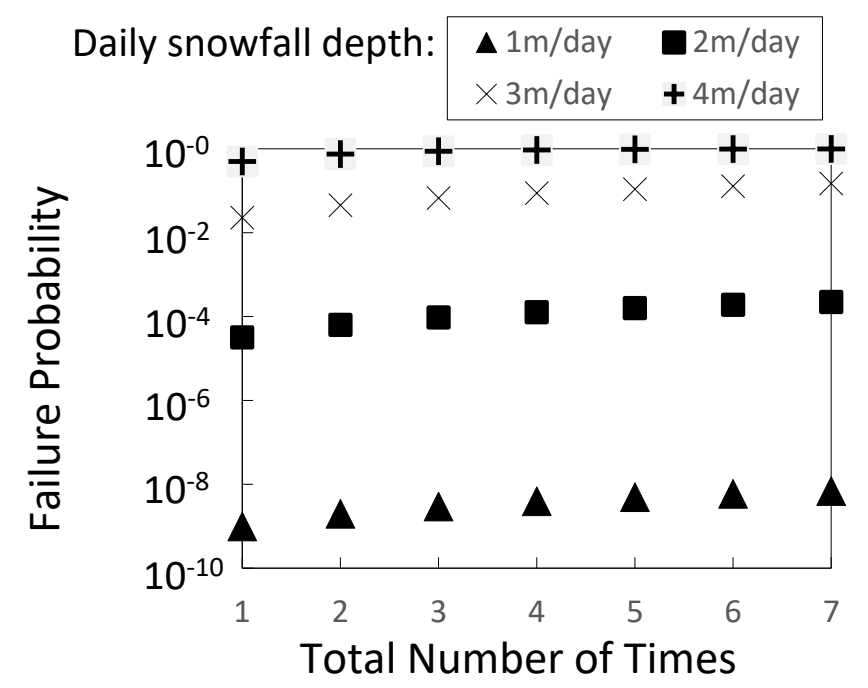

Fig. 6 Corresponding to the increase of snowfall duration time, the total number of times of snow removal increases. As daily snowfall depth and/or total number of times increases, the failure probabilities of snow removal also increases. 


\subsection{Freezing of water in cooling circuits (code AW)}

The water in the circuits is difficult to freeze in a short time even at the low temperature as long as the water circulates in pipes. Here, no water flow was assumed in the circuit by closing a valve due to erroneous operation. If the air temperature stays cold for long hours (1 day or longer), the water could freeze even in the pipes covered by thermal insulation materials. Assuming a tentative pipe of about $45 \mathrm{~mm}$ in diameter, it takes about $75 \mathrm{~h}$ (about 3.1 days) time to freeze water from the initial temperature of $0^{\circ} \mathrm{C}$ when the ambient temperature is $-3^{\circ} \mathrm{C}$ based on a simple hand calculation.

It was assumed that the time to freeze the water is normally distributed under the low temperature condition, and the mean time to freeze the water and its standard deviation are $75 \mathrm{~h}$ and $15 \mathrm{~h}$ (about 0.6 day), respectively. The obtained probability distribution is shown in Fig. 7.

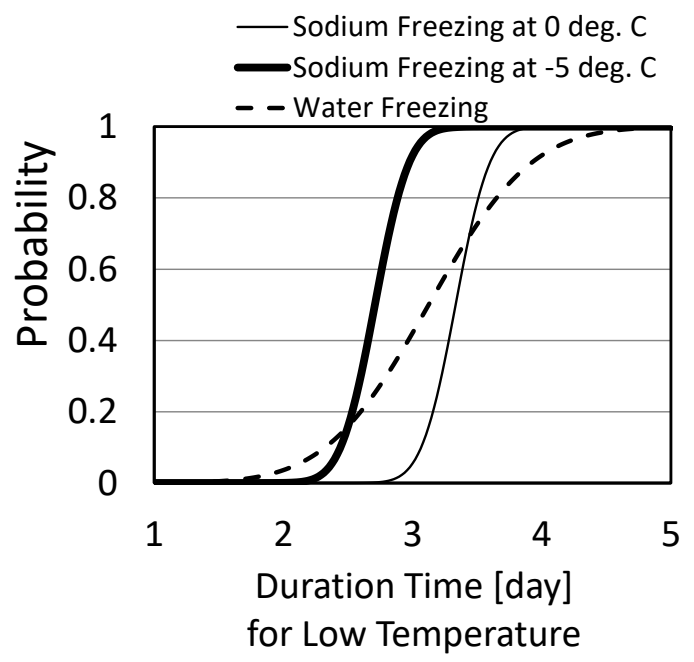

Fig. 7 Three curves show the freezing probability depending on duration time for low temperature. The dash line shows water freezing probability in the cooling circuits. The bold line and fine line show sodium freezing probability at -5 deg.C and at 0 deg.C, respectively.

\subsection{Filter replacement (codes DF and AF)}

The intake filters can be clogged when snow accumulates on them and stays there as ice due to low temperature. The quantity of snow accumulated on the filter is estimated as the product of air flow volume of intake [ $\left.\mathrm{m}^{3} / \mathrm{h}\right]$, snowfall duration time $[\mathrm{h}]$, and atmospheric concentration of snow $\left[\mathrm{kg} / \mathrm{m}^{3}\right]$, where this concentration strongly depends on the daily snowfall depth. Figure 8 shows calculation results of the quantity. When the estimated snow quantity is more than a criterion, the filter is assumed to be clogged. This criterion is defined as the product of filter area $\left[\mathrm{m}^{2}\right]$, snow thickness $[\mathrm{m}]$ at which the filter is completely clogged, and the density of the accumulated frozen snow on the filters $\left[\mathrm{kg} / \mathrm{m}^{3}\right] . \mathrm{The}$ snow density and the snow thickness are assumed to be $0.92 \times 10^{3} \mathrm{~kg} / \mathrm{m}^{3}$ and $0.01 \mathrm{~m}$, respectively.

To prevent the filter failure, plant personnel replace the filters before the estimated quantity of snow reaches the criterion. This study estimated a failure probability of the filter replacement by the formula of failure probability for recovery (AESJ, 2013). Parameters in the formula are the grace time and an average time for filter replacement. It was assumed that the average time is $1.0 \mathrm{~h}$. The grace time, which is time to filter failure, is calculated by dividing the snow quantity $9.2 \mathrm{~kg} / \mathrm{m}^{2}$ by the snow quantity per unit area for unit time. While it is snowing at very low temperature, plant personnel are required to replace the filter many times before the filter is clogged. Required number of minimum times for the filter replacement is determined by dividing the duration time of the combination of snow and low temperature by the grace time. Failure probability of replacing the filters was estimated considering this number. The estimation results are shown in Fig. 9. Now, we explain how to determine the duration time of the combination. Time histories of snow and low temperature are grouped into four types (Fig. 10). Figure 10 also shows that the how long the combination lasts is derived from the duration times of snow and low temperature. In this study, actual time histories of them are not traced; thus we cannot know which type(s) could occur. Assuming type I or II instead of type III or IV, we compare the duration times of snow and low temperature to select the shorter one as that of the combination. 

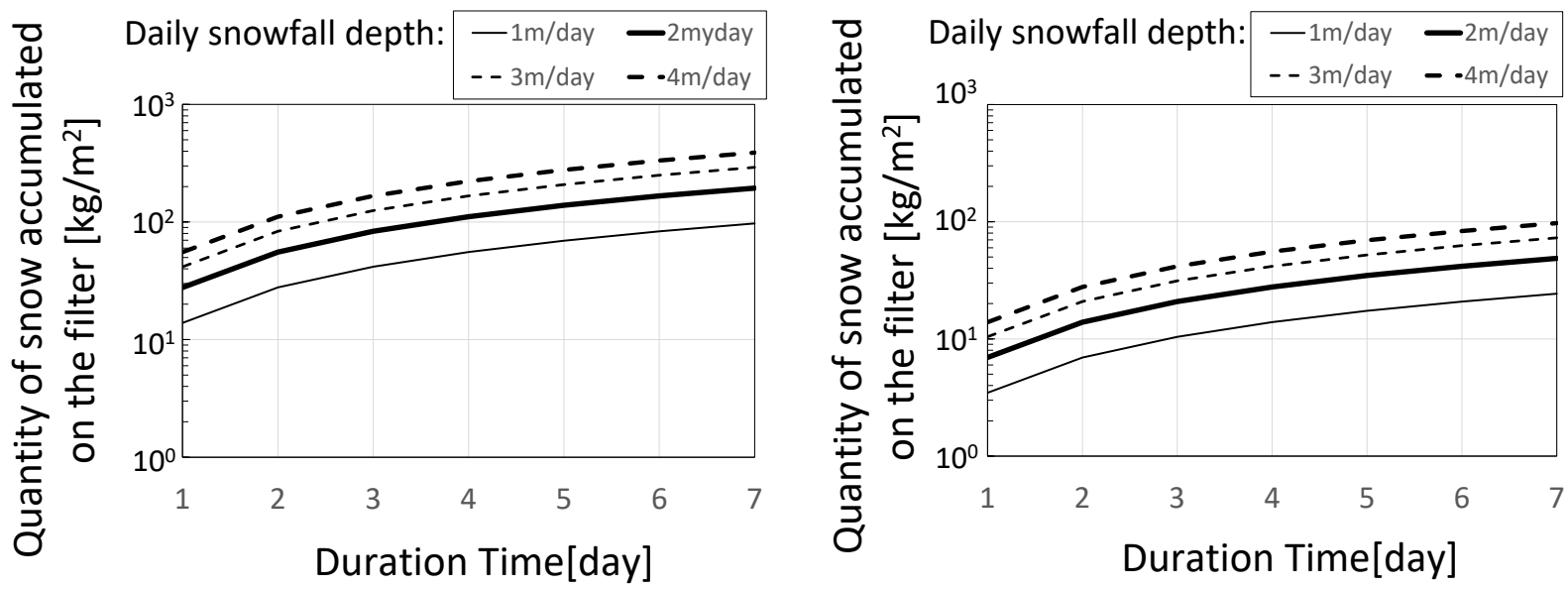

Fig. 8 The curves show relation between duration time of combination hazard and quantity of snow accumulated on the filter for each daily snowfall depth. Left side figure shows the relation for the EDG and right side figure shows the relation for the DHRS. When the snow quantity is more than $9.2 \mathrm{~kg} / \mathrm{m}^{2}$, the filter is clogged.
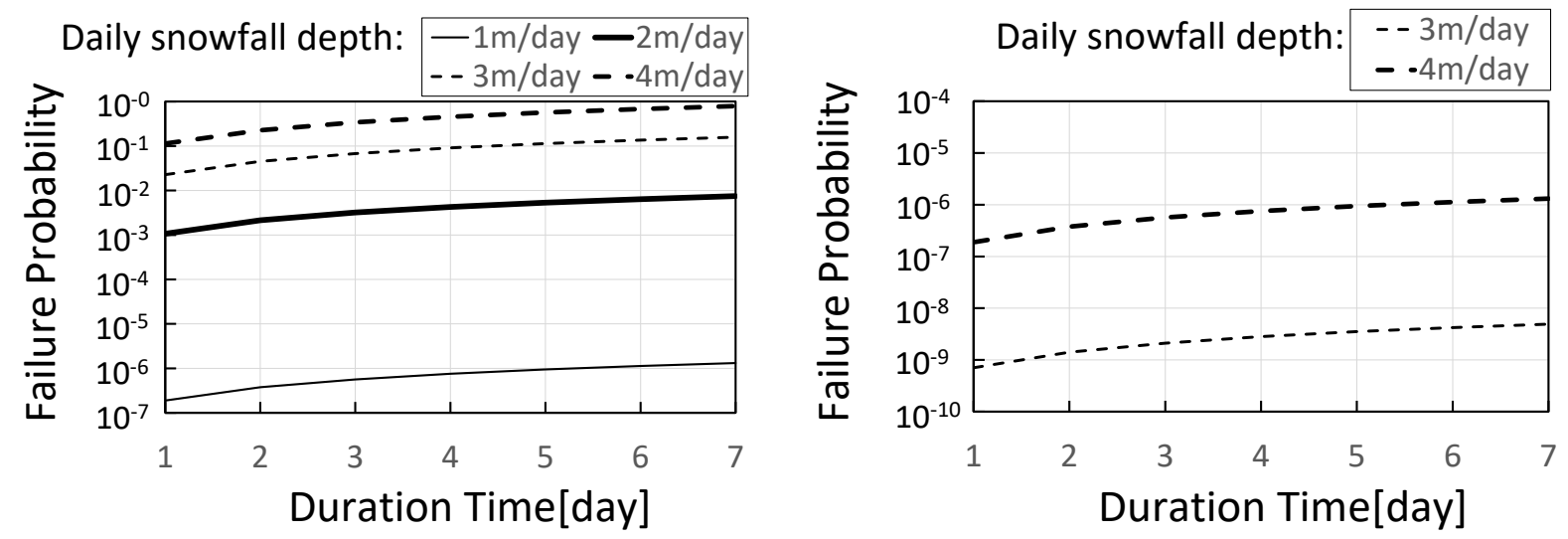

Fig. 9 The curves show relation between duration time of combination hazard and failure probability of filter replacement for each daily snowfall depth. Left side figure shows the relation for the EDG. Right side figure shows the relation for the DHRS and failure probabilities for $1 \mathrm{~m} /$ day and $2 \mathrm{~m} /$ day are less than $10^{-10}$.

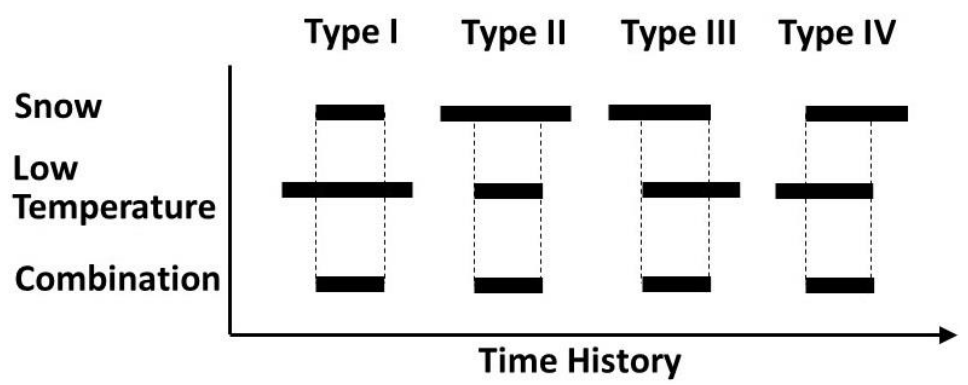

Fig. 10 The length of the bars indicate each duration time of snow, low temperature and their combination. This study calculated duration time of their combination based on type I and II after collecting duration time record of snow and low temperature. Duration time in Fig. 8 and 9 means the calculated duration time.

\subsection{Manual operation of dampers (code D)}

The natural circulation mode requires regulation of all dampers in the three loops of the DHRS. In this study, the regulation failure probability — in the case of the room air temperature of $0^{\circ} \mathrm{C}$ and the low temperature lasts for 1 day- 
is assumed to be about $1.0 \times 10^{-5}$. It becomes more difficult for plant personnel to regulate all the dampers when the low temperature lasts longer and/or the room air temperature becomes $0^{\circ} \mathrm{C}$ or below. Taking these into consideration, this study assumed as follows; 1) the regulation failure probability is in proportion to the low temperature duration time; 2 ) the regulation failure probability at the room air temperature of $-5^{\circ} \mathrm{C}$ is ten times larger than that at $0^{\circ} \mathrm{C}$.

\subsection{Sodium freezing in heat transfer tube (code AN)}

By using a plant dynamics code, change in sodium temperature at the outlet of the DHRS air cooler was numerically analyzed under the condition that the room air temperature is $0^{\circ} \mathrm{C}$ and the all dampers of the DHRS air cooler are fully opened. The analysis result shows that the sodium temperature decreases to about $150^{\circ} \mathrm{C}$ in $65 \mathrm{~h}$ (about 2.7 days), and it approaches to about $120^{\circ} \mathrm{C}$ in $95 \mathrm{~h}$ (about 4.0 days). Based on this result, it was assumed that time to sodium freeze is normally distributed, and mean time minus $3 \sigma$ and mean time plus $3 \sigma$ were assumed to be $65 \mathrm{~h}$ and $95 \mathrm{~h}$ respectively, where $\sigma$ is standard deviation of the normal distribution. The probability distribution is shown in Fig. 7.

In the same way, another analysis was conducted under a different condition of the room air temperature of $-5^{\circ} \mathrm{C}$. The sodium temperature decreases to $150^{\circ} \mathrm{C}$ in $50 \mathrm{~h}$ (about 2.1 days) and $120^{\circ} \mathrm{C}$ in $80 \mathrm{~h}$ (about 3.3 days). Based on this result, mean time minus $3 \sigma$ and mean time plus $3 \sigma$ were assumed $50 \mathrm{~h}$ and $80 \mathrm{~h}$ respectively. The probability distribution is shown in Fig. 7.

\section{Sequence quantification}

The event tree is quantified by using the occurrence frequency of the combination hazard, the failure probability of the SSCs and the failure probability of personnel recovery action. The CDF was estimated to be $5.2 \times 10^{-8} /$ year. The CDFs for dominant hazard category are plotted in Fig. 11. The dominant hazard category is combination of the daily snowfall depth of $1 \mathrm{~m}$ /day to $2 \mathrm{~m}$ /day ( $2 \mathrm{~m}$ /day as representative value), the snowfall duration time of $0 \mathrm{~h}$ to $24 \mathrm{~h}$ ( $1 \mathrm{day}$ as a representative value) and the low temperature duration time of $0 \mathrm{~h}$ to $24 \mathrm{~h}$ ( 1 day as a representative value).

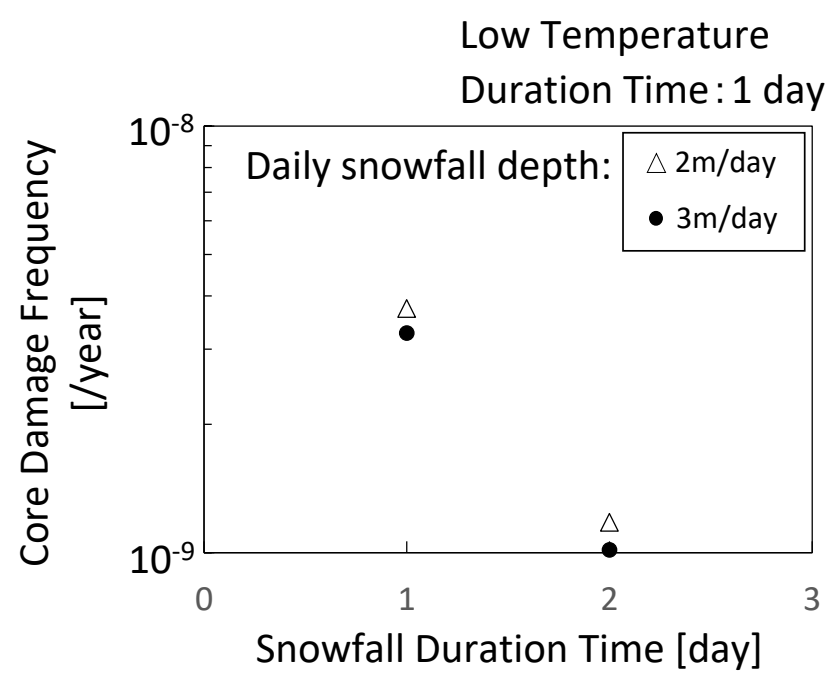

Fig. 11 The plotted symbols show CDFs equal to or higher than 10 hazard categories.

A dominant core damage sequence is the loss of access routes for snow removal followed by multiple failures of the electric heaters around the intakes and outtakes of both the EDG and DHRS or of both the DHRS and alternative DHRS as shown in Fig 12. The other sequences have minor contribution to the CDF and those are caused by effects of low temperature and by interaction of the two natural phenomena. It can be explained as follows. As for low temperature influences, the water freezing in the cooling circuits only affects the EDG; therefore decay heat removal for preventing core damage can be achieved in the natural circulation mode. Although the air cooler fails because its intakes are clogged 
with snow, it fails before the sodium in a heat transfer tube freezes due to overcooling; therefore, the sodium freezing is difficult to arise. In the same way, even if the intakes are clogged with snow and the air cooler loses its function, these events occur before the filters of the intake are clogged due to the interaction of snow and low temperature; therefore, filter clogging is difficult to arise.

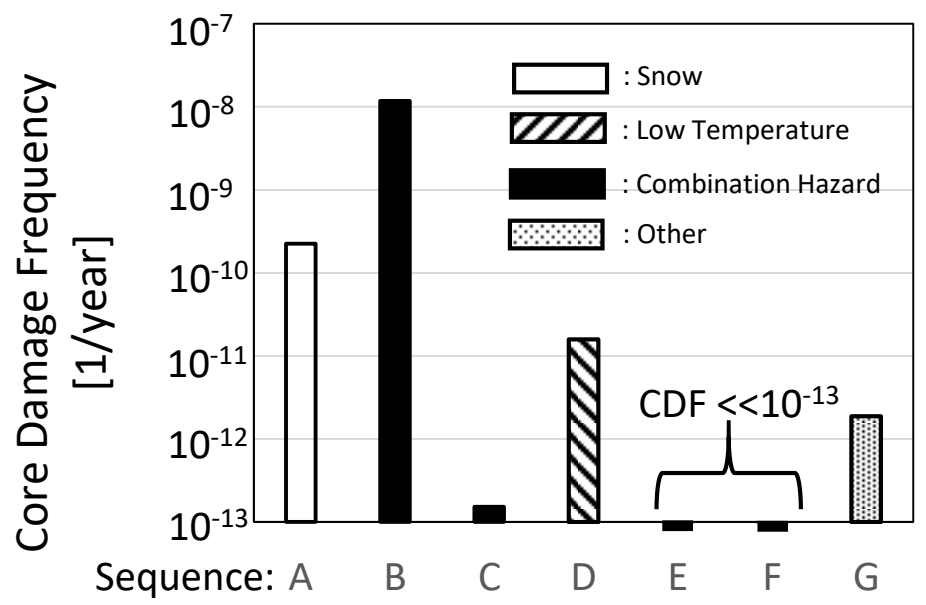

Sequence A:

After securement of access routes, failure of electric heaters and snow removal around intake or outtake for DHRS. Sequence B:

Loss of access routes and failure of electric heaters around intake or outtake for DHRS.

Sequence C:

Failure of filter replacement for EDG and freezing of sodium in the heat transfer tube by failure of operating the dampers manually of the DHRS after filter replacement for DHRS.

Sequence D:

Water freezing in cooling circuits and freezing of sodium in the heat transfer tube by failure of operating the dampers manually of the DHRS after filter replacement for DHRS.

Sequence $\mathrm{E}$ :

Failure of filter replacement for EDG and freezing of sodium in the heat transfer tube by failure of operating the dampers manually and of filter replacement for DHRS.

Sequence F:

Water freezing in cooling circuits and freezing of sodium in the heat transfer tube by failure of operating the dampers manually and of filter replacement for DHRS.

Sequence G:

Failure of the awareness in all the chance.

Fig. 12 Comparison of CDF between core damage sequences in all hazard categories. Code A, B, C, D, E, F, and G in this figure mean sequence in the event tree.

The CDF estimated in this study decreased about 1/10 times than the one estimated in the previous study (Nishino et al., 2017). It suggests that the CDF is significantly affected by whether or not the electric heaters are introduced. If the reliability of the electric heaters is improved, the frequency of sequence "B" shown in Fig. 12 decreases further, resulting in more reduction of total CDF. Therefore, introducing electric heaters is effective countermeasure to decrease the CDF.

The dominant factors and CDF mentioned above might be sensitive to uncertainty in the occurrence frequency estimation of the combination hazard. The significant uncertainty exists in the estimated occurrence frequency in the range of the hazard intensity where there is no observed record (e.g., the range longer than $\sim 50 \mathrm{~h}$ shown in Fig. 1). While the distribution curve was extrapolated to this range, it is favorable to estimate the uncertainty distribution and mean in this range. It is a future work.

This study assumes conservative scenarios and values for parameters comprehensively to show how to apply this new PRA methodology. Studies on quantitative comparison of CDF among various external hazards is also a future work.

\section{Sensitivity analyses}


As mentioned in Section 5, the dominant core damage sequence includes the loss of access routes for the snow removal. If plant personnel do not fail to secure the access routes, the CDF will be lower than the CDF calculated in a basic analysis described in Sections 2 to 5. The probability of the loss of access routes would be sensitive to parameters: the number of chances that plant personnel are aware of the need of snow removal; the time of the first awareness. To research the CDF sensitivity to these parameters, this study compares the CDF calculated in the basic analysis with the CDF obtained in sensitivity analyses for two cases:

Case (i) the number of the chance that plant personnel become aware is more or less than that obtained in the basic analysis;

Case (ii) the time of the first awareness of the need is later than that used in the basic analysis. Sections 6.1 and 6.2 describe Cases (i) and (ii), respectively.

\subsection{Sensitivity to the number of the awareness chance}

When the chance of awareness is less than that used in basic analysis, the CDF is higher than that calculated in the basic analysis. Assuming that the number of the chance decreases to 2 from 3 times, the CDF of the sequence G in Fig. 12 increases to $\sim 2.2 \times 10^{-8}$ /year from $\sim 1.9 \times 10^{-12}$ /year and the sequence $\mathrm{G}$ becomes dominant in all the sequences. In this case, a total CDF is estimated to be $7.5 \times 10^{-8} /$ year and $\sim 1.4$ times higher than that in the basic analysis. When the number of the chance is only 1 , both the CDF of the sequence G in Fig. 12 and a total CDF increase to $\sim 2.6 \times 10^{-4} /$ year. In this case, the total CDF is $\sim 5.0 \times 10^{3}$ times higher than that in basic analysis. On the other hand, when the chance is more than that in the basic analysis, the CDF of the sequence G in Fig. 12 is lower than that calculated in basic analysis.

\subsection{Sensitivity to the point of time of the awareness}

From the results of Section 4.2, it is important to recognize the need of removing snow early to secure the access routes. If the point of time of the awareness is too late, plant personnel fail to open the roof door. To examine the CDF sensitivity for the time of the first awareness, additional analyses were performed as follows.

Sensitivity analysis (1): In this analysis, the chance of the first awareness in the basic analysis is omitted to delay the first and second chances $8.0 \mathrm{~h}$ at which plant personnel actually become aware of the need. As a result, the number of the chance decreased to two. In the CDF calculation, the failure probability of code $\mathrm{H} 1$ in the event tree in Fig. 3 is changed to 1 . The success branch of code H2 in the event tree means the actual first awareness, and the failure probability of opening the roof door after the actual first awareness is given in the 2nd curve in Fig. 5. In the same way, the success branch of code $\mathrm{H} 3$ shows the second awareness, and the failure probability of opening the roof door after the second awareness is determined from the 3rd curve in Fig. 5.

Sensitivity analysis (2): In this analysis, the time of the first and second awareness are the same as ones in the basic analysis, but the third chance is omitted to reduce the number of the awareness chance to two to compare to sensitivity analysis (1). In the CDF calculation, the failure probability of code $\mathrm{H} 3$ in the event tree in Fig. 3 is changed to 1.

The results of sensitivity analyses (1) and (2) are shown in Fig. 13. The difference between the CDFs obtained in the basic analysis and sensitivity analysis (2) derives from the reduction of the chance. On the other hand, the CDFs of sensitivity analyses (1) and (2) have 100 times of difference. These show that it is important for plant personnel to be aware of abnormal snowfall and remove snow as accident management as early as possible to effectively reduce a CDF. 


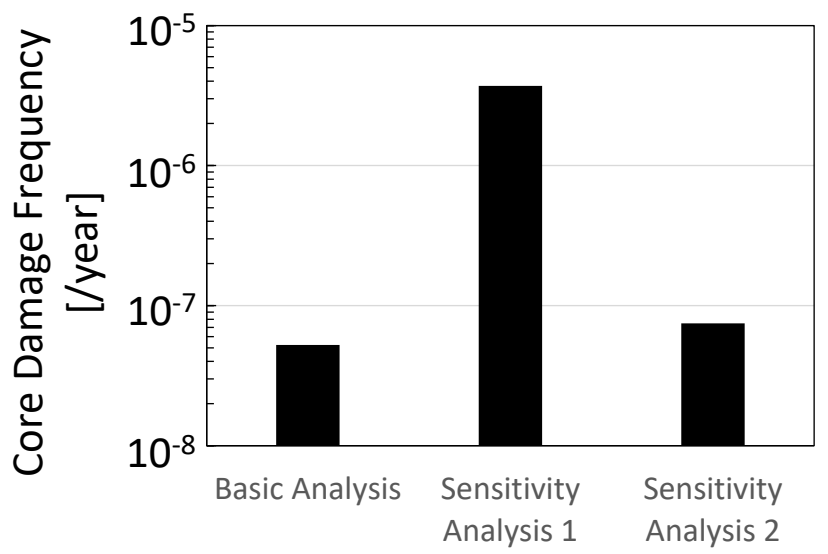

Fig. 13 Comparison of the CDFs between the basic analysis, sensitivity analyses (1) and (2).

\section{Conclusion}

This study has developed a PRA methodology for the combination hazard of snow and low temperature. The annual exceedance probability of low temperature and snow is statistically estimated by using meteorological data of low temperature, snow depth and daily snowfall depth.

An event tree has been developed considering various impacts of low temperature and snow on a DHRS: clogging of the intakes and outtakes of the DHRS and for the EDG; an unopenable door on the access routes caused by accumulated snow; failure of the intake filters caused by accumulated snow; the possibility of water freezing in cooling circuits. Recovery actions, namely, snow removal and filter replacement, to prevent loss of DHRS function were also considered in developing the event tree. Furthermore, this study has investigated the case that electric heaters are introduced as an additional countermeasure, assuming that a dominant contributor of snow risk can be the failure of snow removal around the intakes and outtakes resulting from the loss of access routes.

The quantification of the event tree shows that the CDF is $\sim 10^{-8} /$ year. A dominant hazard category is the combination of the daily snowfall depth of $1 \mathrm{~m}$ /day to $2 \mathrm{~m} /$ day, the snowfall duration time of 0 day to 1 day and the low temperature duration time of 0 day to 1 day. We have found that a dominant core damage sequence was the loss of access routes due to the failure of snow removal which is a result of multiple failures of the electric heaters installed around the intakes and outtakes. Estimating uncertainty in the low occurrence frequency of the combination hazard is future work.

The authors believe that the PRA methodology for the combination hazard developed through this study is informative and will an important role for PRAs for various types of SFRs in the world.

\section{Acknowledgments}

The present study is the result of "Research and Development of Margin Assessment Methodology of Decay Heat Removal Function against External Hazards" entrusted to Japan Atomic Energy Agency by the Ministry of Education, Sports, Science and Technology (MEXT) in Japan. Special thanks are due to H. Sakaba and T. Moriyama of Mitsubishi Heavy Industries, Ltd. for their assistance.

\section{References}

Atomic Energy Society of Japan (AESJ), Implementation standard of seismic probabilistic safety assessment for nuclear power plants: 2007, AESJ-SC-P006:2007 (in Japanese).

Atomic Energy Society of Japan (AESJ), Implementation standard concerning the tsunami probabilistic risk assessment of nuclear power plants: 2011, AESJ-SC-RK004E:2011.

Atomic Energy Society of Japan (AESJ), Implementation standard concerning the probabilistic risk assessment of nuclear power plants with power operation (Level 1 PRA): 2013, AESJ-SC-P008:2013 (in Japanese).

Bareith, A., Karsa, Z., Siklossy, T., and Vida, Z., External events PSA for the paks NPP, Workshop proceedings of 
Probabilistic Safety Assessment (PSA) of natural external hazards including earthquakes, OECD/NEA/CSNI/R (2014)9, pp. 233-242.

Chen, W., The systematic evaluation of combining extreme hazards for Lungmen Nuclear Power Plant, Proceedings of the 13th International Conference on Probabilistic Safety Assessment and Management (PSAM 13) (2016), Paper No. A-044.

Japan Meteorological Agency, Search for Meteorological Data of the Past, available from < http://www.data.jma.go.jp /obd/stats/etrn/index.php?sess=6ef525a9cdef28cea634ce58ca736e68>, (accessed on 30 November, 2016) (in Japanese).

Japan Society of Maintenology (JSM), Guideline to select external events and their combination hazards considered in plant design for light-water reactor nuclear power plant, (written in 2014), available from < http://www.jsm.or. jp/jsm/images/at/report/201409.pdf >, (accessed on 9 February, 2018) (in Japanese).

Kovacs, Z., and Spenlinger, R., Non-seismic external event level 1 PSA for the WWER440 type reactors, Proceedings of the 13th International Conference on Probabilistic Safety Assessment and Management (PSAM 13) (2016), Paper No. A-142.

Kuramoto, T., Yamaguchi, A., Narumiya, Y., Ota, T., and Mamizuka, Y., Development of implementation standard concerning the risk evaluation methodology selection for the external hazards, Proceedings of the 12th International Conference on Probabilistic Safety Assessment and Management (PSAM 12) (2014), Paper No. 298.

Narumiya, Y., Nomura, H., Nakayama, T., Hashimoto, N., Terasaki, Y., Mamizuka, Y., Hirosawa, T., Shinzaki, S., Kuramoto, T., and Hijiya, M., A study of screening method for the risk significant combinations among the external hazards, Proceedings of the 13th International Conference on Probabilistic Safety Assessment and Management (PSAM 13) (2016), Paper No. A-552.

Nishino, H., Yamano, H., and Kurisaka, K., Research and development of probabilistic risk assessment methodology for combination event of low temperature and snow, Transactions of the JSME (in Japanese), Vol.83, No.847 (2017), Doi : 10.1299/transjsme.16-00392.

Puuka, T., Pesonen, J., Tarkiainen, A., and Tuulensuu, H., External hazard in the PRA of Olkiluoto NPP units 1 and 2 and interim storage for spent nuclear fuel - ongoing actions in the light of the Fukushima accident, Proceedings of the International Topical Meeting on Probabilistic Safety Assessment and Analysis (PSA 2015), Paper No. 099.

Tamori, K. and Kyoshi, T., A research on optimization of plotting position, Transaction of Japan Society of Civil Engineers, Paper No.66, B-27 (2009) (in Japanese).

Yamano, H., Nishino, H., Kurisaka, K., Development of probabilistic risk assessment methodology against extreme snow for sodium-cooled fast reactor, Nuclear Engineering and Design (2016), Vol.308, No.11, pp.86-95. 